\title{
RETALIAÇÃO: ANÁLISE DAS ATITUDES DOS SERVIDORES DE UMA INSTITUIÇÃO DE ENSINO SUPERIOR PÚBLICA
}

\author{
RETALIATION: ANALYSIS OF THE ATTITUDES OF THE SERVANTS OF AN \\ INSTITUTION OF PUBLIC HIGHER EDUCATION
}

\author{
Doneide Kaufmann Grassi \\ Universidade Federal de Santa Maria, Santa Maria, RS, Brasil. \\ E-mail:doneidekg@gmail.com \\ Luciana Flores Battistella \\ Universidade Federal de Santa Maria, Santa Maria, RS, Brasil. \\ E-mail: lutti@ufsm.br \\ Patrícia Nunes Pezzini \\ Universidade Federal de Santa Maria, Santa Maria, RS, Brasil. \\ E-mail: patriciapezzini@ufsm.br
}

Recebido em: 19.11.2018 - Aceito em: 27.08.2018

DOI: http://dx.doi.org/10.5902/2526629230025

\section{RESUMO}

A justiça constitui um instrumento fundamental para a garantia da harmonia nas relações humanas. A falta de justiça, em especial em organizações, pode determinar atitudes que propiciam comportamentos disfuncionais, como a retaliação. O presente artigo objetiva avaliar a atitude retaliatória em uma instituição de ensino superior pública. A pesquisa caracteriza-se por ser de natureza quantitativa e de caráter descritivo. O instrumento utilizado foi a escala MARO (Medidas de Atitudes em Relação à Retaliação Organizacional), a qual é composta por dois constructos: comportamentos afetivo e conativo. Por meio de um cenário hipotético-conceitual, os respondentes posicionaram-se em relação a um caso descrito. Em termos de percepção do comportamento afetivo, identificou-se uma média que aponta para indignação dos respondentes diante da situação de injustiça descrita; em contrapartida, quanto ao componente conativo, a média foi indicativa de um comportamento de não retaliação à organização.

PALAVRAS-CHAVE: Retaliação organizacional; Atitudes retaliatórias; Justiça.

\section{ABSTRACT}

Justice is a fundamental instrument for guaranteeing harmony in human relations. Lack of justice, especially in organizations, can determine attitudes that lead to dysfunctional behavior, such as retaliation. Tthe present article aims to evaluate 
the retaliatory attitude in a public higher education institution. The research is characterized by being of a quantitative and descriptive nature. The instrument used was the MARO - Attitudes Measures in Relation to Organizational Retaliation, which is composed of two constructs: affective and conative behavior. Through a hypothetical-conceptual scenario, respondents positioned themselves in relation to a case described. In terms of the perception of the affective behavior, an average was identified that points to the indignation of the respondents in face of the situation of injustice described; In contrast, for the conative component, the mean was indicative of a behavior of non-retaliation to the organization.

KEYWORDS: Organizational retaliation; Retalatory attitudes; Justice.

\section{INTRODUÇÃO}

Permeando quase todos os aspectos de nossa vida, a justiça constitui um instrumento fundamental para a garantia da harmonia nas relações que se estabelecem em sociedade. Assim como em outros espaços da sociedade, o ambiente organizacional também consiste em uma complexa teia de interações entre os diferentes sujeitos que o compõem, os quais trazem consigo um conjunto distinto de valores e concepções, muitas vezes fazendo emergir conflitos e situações de injustiça.

A partir da década de 1960, com o surgimento da Psicologia Social da Justiça, pesquisadores vêm se preocupando em demonstrar o que é justo ou injusto no ambiente organizacional. Nesse sentido, a pesquisa científica vem empenhando esforços em desenvolver estudos na área que possibilitem uma melhor compreensão desses comportamentos; mais especificamente, na última década do século $X X$, é que os estudiosos têm se interessado pelos comportamentos de reações à injustiça no local de trabalho.

Ao vivenciar uma experiência de injustiça, as pessoas reagem de algum modo. Essa reação pode gerar uma força contrária, caracterizando comportamentos disfuncionais, que surgem quando os indivíduos sentem seus direitos naturais desrespeitados. Esses comportamentos podem causar prejuízos ou impactos diretos ou indiretos às organizações e às pessoas. Com relação à organização, podem gerar atitudes contraproducentes, ou seja, pode ocorrer um boicote de atividades que necessitam ser realizadas ou contribuir para expressões de raiva ou propagação de atitudes retaliatórias, difundindo um ambiente de trabalho hostil e gerando, assim, perda de produtividade e elevados custos de mão de obra. Com relação às pessoas, tais comportamentos podem propiciar um ambiente de baixa justiça organizacional, que impacta na saúde do trabalhador (Mendonça \& 
Tamayo, 2008).

Segundo Mendonça (2008, p. 249), o conceito de retaliação refere-se à lei de talião, que remete ao antigo ditado popular "olho por olho, dente por dente" e significa revanche, isto é, "aqui se faz, aqui se paga". De acordo com Skarlicki e Folger (1997), os comportamentos retaliatórios ocorrem com o objetivo de punir as organizações ou seus representantes quando as pessoas percebem que estão sendo tratadas injustamente no trabalho e se sentem insatisfeitas diante de tal situação.

Este estudo busca compreender a retaliação, um dos tipos de comportamento disfuncional, no âmbito de uma instituição de ensino superior federal. As instituições públicas carecem de maiores estudos comportamentais, que busquem nortear projetos e práticas de gestão capazes de minimizar os impactos negativos de ações disfuncionais e que busquem resgatar os servidores de processos viciosos para círculo virtuoso.

A maioria dos estudos organizacionais é direcionada para os comportamentos positivos dos indivíduos, relacionados, sobretudo, à produtividade e à eficácia. Em contrapartida, os comportamentos negativos ou disfuncionais, como as atitudes retaliatórias, que estão diretamente ligados à ineficácia e refletem em altos custos para as organizações, passaram a receber maior atenção dos pesquisadores da área organizacional apenas a partir do final da década de 1990 (Mendonça \& Tamayo, 2008).

Nesse contexto, surge o seguinte problema de pesquisa: como os servidores de determinada instituição federal de ensino superior reagiriam diante de uma situação de injustiça no trabalho? Este estudo justifica-se como forma de colaborar para o desenvolvimento desse tópico, especialmente no sentido de que as instituições públicas, por meio de políticas de gestão de pessoas, devem buscar a solução de conflitos e pautar suas ações na justiça organizacional.

A presente pesquisa tem como objetivo geral avaliar a atitude retaliatória em uma instituição de ensino superior pública. São objetivos específicos da pesquisa: 1) apresentar os resultados do componente afetivo da atitude retaliatória; 2) apresentar os resultados do componente conativo da atitude retaliatória; 3) discutir a influência do perfil dos respondentes sobre as atitudes retaliatórias.

A fim de atingir o objetivo proposto, este trabalho foi estruturado em outras quatro seções, além desta introdução. A segunda seção apresenta a fundamentação teórica da pesquisa, com os aspectos teórico-conceituais relacionados à temática. Na terceira seção, é apresentado o método de pesquisa utilizado para sua consecução. Na sequência, a quarta seção compreende a apresentação e discussão dos resultados obtidos. Por fim, são apresentadas as considerações 
finais, elaboradas a partir da pesquisa realizada.

\section{REFERENCIAL TEÓRICO}

\subsection{Justiça e retaliação organizacional}

A justiça permeia quase todos os aspectos de nossa vida. Conforme Rego (2001, p. 119), ela está "indelevelmente inscrita na vida social humana, não poderia deixar de está-lo também na vida organizacional".

Segundo Mendonça e Tamayo (2004, p. 125), os estudos sobre retaliação apresentam como principal antecedente a percepção de justiça. Dessa forma, antes de se falar em retaliação, há que se abordar a justiça. A partir da década de 1960, com o surgimento da Psicologia Social da Justiça, pesquisadores dessa área vêm empreendendo esforços em pesquisas que buscam compreender as percepções dos trabalhadores acerca do que é considerado justo ou injusto nas relações que se estabelecem no contexto organizacional, quais as influências dessas concepções subjetivas e como elas afetam suas atitudes e comportamentos (Assmar, Ferreira, \& Souto, 2005).

Em 1961, Homans foi o primeiro teórico a trazer contribuições para os estudos relacionados à justiça, afirmando que

o homem espera receber suas recompensas de forma proporcional às relações de troca que estabelece com seus colegas de trabalho: uma relação econômica, de forma que as recompensas ou o lucro crescem de acordo com os investimentos e os custos (Homans, 1961 citado por Mendonça \& Tamayo, 2004, p. 125).

Adams (1963) identificou que indivíduos que se sentiam em situações injustas, desenvolveram determinadas maneiras comportamentais com o intuito de modificar tal situação. Os estudos sobre justiça organizacional têm ampliado o conhecimento sobre as diferentes formas que as reações às injustiças podem adquirir, demonstrando o poder investigativo desse construto para a compreensão de atitudes e comportamentos organizacionais.

Jerald Greenberg (citado por Assmar et al., 2005), a partir de 1987, reuniu estudos sobre as concepções, percepções e reações à (in)justiça por parte dos empregados em relação às organizações em que trabalham, cunhando o termo "Justiça Organizacional".

O tratamento injusto traz resultados desfavoráveis: constitui-se em um desrespeito e provoca a indignação do trabalhador, podendo resultar em atitudes retaliatórias de sua parte. Diante da vivência em situações desfavoráveis, como um 
salário mais baixo do que o esperado, a hostilidade no tratamento interpessoal dado pela chefia ou, ainda, a não participação em processo de promoção, ocorre o descontentamento, a indignação. Algumas situações provocam sofrimento psíquico, ameaçam o bem-estar do trabalhador, impactando diretamente na qualidade de vida das pessoas.

Nesse sentido, pode-se afirmar que a justiça constitui um instrumento fundamental para a garantia da harmonia nas relações que se estabelecem nesse ambiente, pois, segundo Assmar et al. (2005, p. 443), "a justiça organizacional desempenha papel vital na saúde dessas relações [...] ela constitui requisito básico para o funcionamento eficaz das organizações e a satisfação pessoal de seus membros".

A retaliação pode ocorrer em diferentes contextos, abrangendo relações interpessoais, organizacionais e até mesmo societais (Mendonça, 2008, p. 249). No contexto organizacional, a retaliação tem sido definida como resposta às experiências de injustiça vivenciadas pelos trabalhadores (Mendonça \& Tamayo, 2004, p. 119). Ainda segundo esses autores, a retaliação pode se manifestar de duas formas: "de maneira explícita, ocorre por meio de atos agressivos e flagrantes, como agredir verbalmente um colega de trabalho; de maneira sutil, na forma de boicotes ao bom desempenho organizacional" (Mendonça \& Tamayo, 2008, p. 192).

Skarlicki e Folger (1997) foram pioneiros nos estudos empíricos sobre Comportamentos de Retaliação Organizacional (CROs). Tais estudos deram enfoque aos comportamentos negativos utilizados pelos empregados para punir a organização e seus representantes pelas injustiças sentidas e percebidas pelos trabalhadores. Uma escala, elaborada pelos autores, foi desenvolvida levando em conta a realidade de uma única organização, dificultando, dessa forma, a generalização para outros contextos. Skarlicki e Folger (1997) definiram retaliação como um subconjunto dos comportamentos negativos que ocorrem com o objetivo de punir a organização ou seus representantes, em resposta à injustiça percebida.

Nesse sentido, Towsend, Phillips e Elkins (2000) reforçaram a teoria no que diz respeito à justiça interacional ao relacionar a retaliação à troca insatisfatória entre chefias e subordinados. Conforme esses pesquisadores, a retaliação pode ser direcionada aos colegas, aos chefes ou à organização, podendo ocorrer, também, de forma sutil, na tentativa de restaurar a percepção de justiça. De acordo com Tamayo e Mendonça (2008), a definição de Towsend et al. (2000) é incompleta por tratar apenas da retaliação como consequência de relações interpessoais de troca insatisfatórias entre chefias e subordinados.

No entanto, os instrumentos de medida utilizados tanto por Skarlicki e Fol- 
ger (1997) quanto por Mendonça e colaboradores (não publicado) mostraram-se insuficientes para avaliar o posicionamento dos trabalhadores em relação à retaliação organizacional, sobretudo em um contexto explícito de injustiça (Mendonça \& Tamayo, 2003, p. 148).

Diante disso, Mendonça e Tamayo (2003) construíram e validaram psicometricamente uma medida que aferisse a atitude de trabalhadores em relação à retaliação organizacional: a Medida de Atitude em Relação à Retaliação Organizacional (MARO), a qual é formada por um cenário hipotético-conceitual que apresenta uma situação que pode ser considerada injusta no contexto organizacional e que pode provocar reações retaliatórias por parte dos trabalhadores. Essa escala constitui o instrumento de coleta de dados desta pesquisa e será descrita a seguir, na seção relativa ao método de pesquisa.

\section{MÉTODO DE PESQUISA}

Quanto à abordagem do problema, a presente pesquisa caracteriza-se pela perspectiva quantitativa, pois esta tem como característica principal a mensuração de algo ou a exposição numérica de tendências, atitudes ou opiniões de uma população. De acordo com Matias-Pereira (2016), no método quantitativo, a coleta de informações e/ou o tratamento destas pressupõe sua quantificação, sendo que os dados são analisados através de técnicas estatísticas. Ainda, segundo Lakatos e Marconi (2011, p. 190), a pesquisa quantitativa é "a mais apropriada para apurar atitudes e responsabilidades dos entrevistados, uma vez que emprega questionários. [...] Seu objetivo é medir e permitir o teste de hipóteses, evitando possíveis erros de interpretação".

Em relação aos objetivos, a pesquisa caracteriza-se como de natureza descritiva, pois tem como finalidade a descrição das características de determinada população ou o estabelecimento de relações entre variáveis (Gil, 2008, p. 28).

No que se refere ao método de amostragem, optou-se por realizar uma amostragem não probabilística por conveniência, a fim de que as informações fossem obtidas de maneira mais rápida. Segundo Gil (2008, p. 94), nesse tipo de amostragem "o pesquisador seleciona os elementos a que tem acesso, admitindo que estes possam, de alguma forma, representar o universo".

O lócus da pesquisa foi uma Instituição Federal de Ensino Superior (IFES), sendo que a população-alvo foi constituída por uma amostra aleatória dos servidores dessa instituição, escolhidos entre os contatos das pesquisadoras.

A IFES analisada foi criada pela Lei $n^{\circ} 3.834-C$, de 14 de dezembro de 1960, com a denominação de Universidade de Santa Maria; em 1965, federalizou-se, 
pela Lei $n^{\circ} 4.759 / 65$. A instituição foi a primeira universidade federal brasileira a ser criada fora das capitais. A atual estrutura estabelece a constituição de 11 Unidades Universitárias e três Unidades de Educação Básica, Técnica e Tecnológica, com 4.769 servidores e 23.599 alunos considerando-se alunos de graduação (presencial e a distância), pós-graduação e educação básica (Universidade Federal de Santa Maria [UFSM], 2017). A instituição tem como missão construir e difundir conhecimento, comprometendo-se com a formação de pessoas capazes de inovar e contribuir com o desenvolvimento da sociedade de modo sustentável.

Como instrumento de coleta de dados, foi utilizado o questionário. Segundo Gil (2008, p. 121), o questionário "é uma técnica de investigação composta por um conjunto de questões que são submetidas a pessoas com o propósito de obter informações sobre conhecimentos, crenças, sentimentos, valores, [...] comportamento presente ou passado, etc.".

O questionário aplicado foi elaborado por meio do Google Formulários e enviado digitalmente aos sujeitos da pesquisa, por e-mail e por contato privado em uma rede social, para 446 servidores da IFES, no período de 16 a 31 de julho de 2017. O instrumento foi estruturado em duas seções, sendo que a primeira abarcou questões sociodemográficas que objetivaram a identificação do perfil dos sujeitos da pesquisa, enquanto a segunda seção foi composta pela escala MARO (Mendonça \& Tamayo, 2003).

A MARO é formada por um cenário hipotético-conceitual que apresenta uma situação que pode ser considerada injusta no contexto organizacional e que pode provocar reações retaliatórias por parte dos trabalhadores (Mendonça, 2008, p. 251). Essa medida foi construída com base nas definições clássicas de atitude, pelas quais elas são conceituadas como avaliação, afeto, cognição e predisposições comportamentais (Olson \& Zanna, 1993 citado por Mendonça \& Tamayo, 2003, p. 149).

O cenário hipotético-conceitual elaborado por Mendonça e Tamayo (2003) para a MARO teve como base o modelo sociocognitivo de Feather (1998 citado por Mendonça \& Tamayo, 2003), que propõe a utilização de cenários com situações concretas, pois considera que atitudes e crenças sobre eventos e resultados são influenciadas por julgamentos que envolvem considerações de justiça.

A Figura 1 apresenta o cenário hipotético-conceitual utilizado no instrumento aplicado nesta pesquisa, com o objetivo de analisar a atitude dos respondentes diante de reações retaliatórias contra a injustiça organizacional. 
Figura 1 - Cenário hipotético-conceitual

Joấo recebe um memorando do chefe, no cual está escrito

"Gostaria de comunicar cue a instituicalo irá promover uma pessoa deste setor

Várias pessoas tem sido consideradas, mas apenas uma será promovida. Com base

em minhas avaliaçoes, decidi ind car Maria."

As outras pessoas do setcr, assim como Joalo, nầo sabiam que haveria aquela promoção e nầo fol perguntada a opiniấo de ninguem sobre quem seria a pessoa mals indicada para assumir aquela nova posiçlo. Jollo se sentiu multo injustiçado, pois ele era muito dedicado e competente. mas nem sequer ouviram a sua cpinilio. Com isso, ele passou a se comportar da seguinte maneira:

- Deixar de expor as suas melhores ideias em relaçäo ao trabalho:

- Fingir que está doente para faltar ao servico:

- Confrontar a chefia.

- Fazer corpo mole.

Fonte: Elaborada pelas autoras com base em Mendonça (2008, p. 261).

O cenário apresentado na Figura 1 teve algumas adaptações em relação ao original, considerando o contexto da instituição pesquisada e as especificidades do setor público objetos deste estudo.

Além desse cenário hipotético, dois componentes constituem a Medida de Atitude em relação à Retaliação Organizacional: comportamento afetivo (7 variáveis) e comportamento conativo (5 variáveis).

O Quadro 1 apresenta os fatores que compõem a escala utilizada nesta pesquisa, suas definições, além das 12 afirmações que compuseram o questionário aplicado. Para melhor visualização, as afirmações foram agrupadas dentro dos respectivos componentes (afetivo e conativo), sendo que algumas delas tiveram pequenas adequações para aplicação da pesquisa em relação à escala original, em função do contexto da instituição pesquisada. 
Quadro 1 - Denominação dos fatores, definições e afirmações do construto

\begin{tabular}{|c|c|c|}
\hline Inação & Definição & Afirmações \\
\hline $\begin{array}{l}\text { Com } \\
\text { conat }\end{array}$ & $\begin{array}{l}\text { Refere-se à tendência } \\
\text { consciente para atuar e } \\
\text { engloba a avaliação posi- } \\
\text { tiva das retribuições, bem } \\
\text { como a crença de que a } \\
\text { empresa merece a reação } \\
\text { e de que ela atuaria de } \\
\text { maneira idêntica diante } \\
\text { de situações de injustiça. }\end{array}$ & $\begin{array}{l}\text { 2. Eu acho que a instituição mereceu o que } \\
\text { João fez. } \\
\text { 4. Eu aprovo o que João fez. } \\
\text { 7. Eu faria a mesma coisa que João fez. } \\
\text { 9. Eu considero a reação de João justa. } \\
\text { 12. Eu acho que João está correto na manei- } \\
\text { ra de agir. }\end{array}$ \\
\hline $\begin{array}{l}\text { Compon } \\
\text { afetivo }\end{array}$ & $\begin{array}{l}\text { Refere-se à indignação } \\
\text { diante do contexto orga- } \\
\text { nizacional em que a reta- } \\
\text { liação ocorre e engloba a } \\
\text { crença de que a injustiça } \\
\text { provoca ressentimento. } \\
\text { Abrange o julgamento da } \\
\text { situação como decepcio- } \\
\text { nante e desprezível, as- } \\
\text { sim como o sentimento } \\
\text { de seriedade da injustiça } \\
\text { cometida. }\end{array}$ & $\begin{array}{l}\text { 1. Eu acho injusto o que a instituição fez com } \\
\text { João. } \\
\text { 3. Eu ficaria desapontado(a) se a instituição } \\
\text { onde trabalho agisse comigo da forma descrita. } \\
\text { 5. Eu acho que este tipo de situação faz com } \\
\text { que as pessoas que não foram beneficiadas } \\
\text { sintam raiva. } \\
\text { 6. Eu ficaria insatisfeito(a) se a instituição onde } \\
\text { trabalho fizesse comigo a mesma coisa que fez } \\
\text { com João. } \\
\text { 8. Eu acho muito sério o que a instituição fez. } \\
\text { 10. Eu ficaria decepcionado(a) se a instituição } \\
\text { onde trabalho fizesse comigo a mesma coisa. } \\
\text { 11. Eu considero desprezível o que a instituição } \\
\text { fez com João. }\end{array}$ \\
\hline
\end{tabular}

Fonte: Adaptado de Mendonça (2008, p. 257, 261-262).

O componente afetivo corresponde ao sentimento de indignação, englobando a crença de que a injustiça provoca ressentimento. Além disso, abrange o julgamento da situação como decepcionante e desprezível e o sentimento de seriedade da injustiça cometida. Já o componente conativo, segundo os autores, "refere-se à tendência consciente para atuar e engloba a avaliação positiva das retribuições, a crença de que a empresa merece a reação e de que ela atuaria de maneira idêntica diante de situações de injustiça" (Mendonça \& Tamayo, 2003, p. 149).

A pesquisa obteve 166 respostas, sendo que, a partir do tratamento do banco de dados, não houve necessidade de desconsiderar nenhuma delas. Assim, todas as análises foram baseadas em uma amostra total de 166 participantes, todos servidores da instituição pesquisada.

No que tange à análise dos resultados, após a coleta, os dados foram tabulados com o apoio do software Microsoft Excel 2010, sendo que posteriormente se procedeu à análise e à realização dos testes estatísticos por meio do software 
SPSS 20 (Statistical Package for the Social Sciences).

Primeiramente, realizou-se a análise do perfil dos respondentes, por meio de estatística descritiva. A seguir, foram analisadas médias e desvios relativos às atitudes retaliatórias, incluindo as médias gerais das duas dimensões de retaliação pesquisada, a média geral do comportamento retaliatório afetivo e do comportamento retaliatório conativo. Por fim, foi realizado o Teste t para diferença entre sexo e ocupantes de cargos de chefia. Os resultados serão apresentados a seguir.

\section{APRESENTAÇÃO E DISCUSSÃO DOS RESULTADOS}

\subsection{Perfil dos respondentes}

Os dados apresentados nesta seção constituem a caracterização dos sujeitos da pesquisa.

A Figura 2 apresenta o gráfico com a análise relativa à idade dos participantes, evidenciando que a faixa etária com maior representação é a que se encontra entre 30 e 39 anos, correspondente a 33,1\% do total, seguida dos servidores que possuem de 50 a 59 anos e de 40 a 49 anos, que representam $28,3 \%$ e $20,5 \%$, respectivamente. Os mais jovens, na faixa etária de 18 a 29 anos, representam 10,8\% da amostra, e a menor parcela é a composta pelos participantes de maior idade, com as faixas etárias de 60 a 69 anos, com $6,6 \%$ do total, e de 70 anos ou mais, com apenas $0,6 \%$.

Figura 2 - Faixa etária dos respondentes

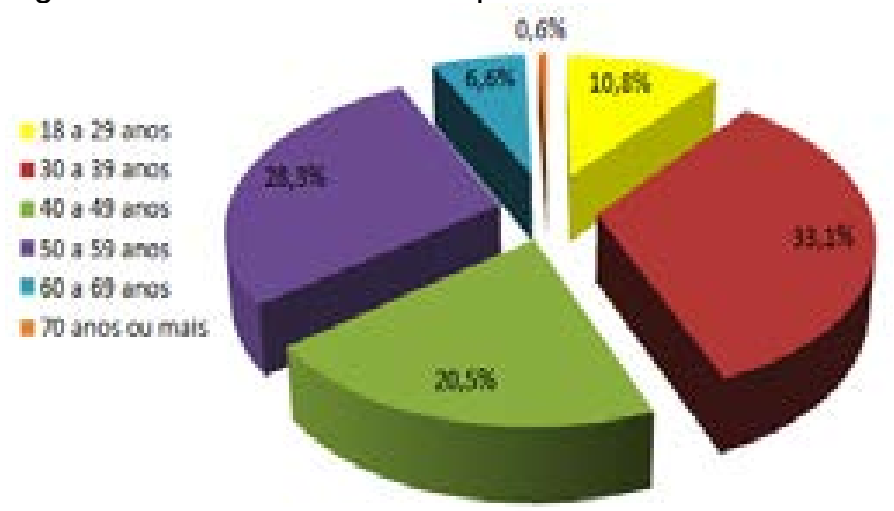

Fonte: Elaborada pelas autoras, conforme dados da pesquisa.

Quanto à escolaridade dos respondentes, apresentada na Figura 3, os dados demonstram que a maioria dos sujeitos possui Graduação, correspondendo a 38\% da amostra; 28,9\% possuem Especialização; 16,3\%, Mestrado; e 11,4\% possuem Ensino Médio. As demais alternativas não apresentaram resultados tão 
significativos: 3,6\% possuem Doutorado e 1,8\% possui o Ensino Fundamental. Figura 3 - Grau de escolaridade dos respondentes

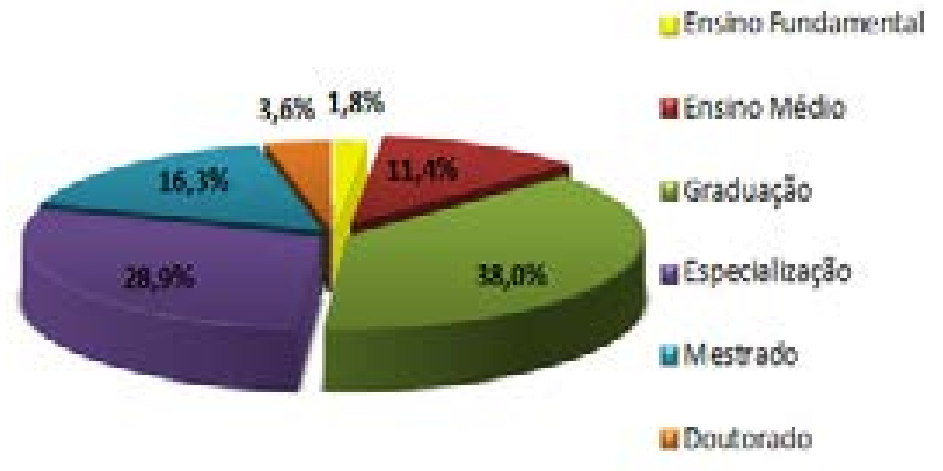

Fonte: Elaborada pelas autoras, conforme os dados da pesquisa.

A Tabela 1 apresenta a distribuição absoluta e relativa dos respondentes quanto à lotação.

Tabela 1 - Distribuição absoluta e relativa dos respondentes quanto à lotação

\begin{tabular}{ccc}
\hline Unidade $^{1}$ & Frequência & $\%$ \\
\hline Reitoria & 96 & 57,8 \\
\hline CAL & 3 & 1,8 \\
\hline CCNE & 5 & 3,0 \\
\hline CCR & 6 & 3,6 \\
\hline CCS & 18 & 10,8 \\
\hline CCSH & 7 & 4,2 \\
\hline CE & 4 & 2,4 \\
\hline CEFD & 3 & 1,8 \\
\hline CT & 5 & 3 \\
\hline CTISM & 2 & 1,2 \\
\hline Politécnico & 3 & 1,8 \\
\hline HUSM & 6 & 3,6 \\
\hline Ipê Amarelo & 1 & 0,6 \\
\hline Campus Cachoeira do Sul & 1 & 0,6 \\
\hline Campus Frederico Westphalen & 2 & 1,2 \\
\hline Campus Palmeira das Missões & 3 & 1,8 \\
\hline UDESSM & 1 & 0,6 \\
\hline Total & 166 & $\mathbf{1 0 0}$
\end{tabular}

Fonte: Elaborada pelas autoras, conforme os dados da pesquisa.

${ }^{1}$ Nota: As siglas apresentadas na Tabela 1 correspondem às unidades da IFES pesquisada, a saber: Reitoria $=$ Prédio da Administração Central; $C A L=$ Centro de Artes e Letras; $\mathrm{CCNE}=$ Centro de Ciências Naturais e Exatas; $\mathrm{CCR}=$ Centro de Ciências Rurais; $\mathrm{CCS}=$ Centro de Ciências da Saúde; $\mathrm{CCSH}=$ Centro de Ciências Sociais e Humanas; $\mathrm{CE}$ = Centro de Educação; CEFD = Centro de Educação Física e Desportos; 
CT = Centro de Tecnologia; CTISM = Colégio Técnico Industrial de Santa Maria; Politécnico = Colégio Politécnico da UFSM; HUSM = Hospital Universitário de Santa Maria; Ipê Amarelo = Unidade de Educação Infantil Ipê Amarelo; UDESSM = Unidade Descentralizada de Silveira Martins.

A partir dos dados apresentados na Tabela 1, pode-se perceber que a maioria dos respondentes $(57,8 \%)$ está lotada junto à Reitoria da instituição pesquisada. A segunda maior representatividade corresponde ao Centro de Ciências da Saúde, com $10,8 \%$ do total. As demais unidades não apresentaram resultados significativos. Tal discrepância nos dados pode ser explicada pelo fato de que a amostra foi formada pelos contatos das pesquisadoras, constituindo uma amostra não probabilística, sendo que as pesquisadoras trabalharam ou trabalham nas unidades citadas.

Já a Tabela 2 demonstra os demais dados sociodemográficos da pesquisa, relativos às características de gênero, categoria funcional, função de chefia, situação funcional, estado civil, tempo de trabalho e renda bruta.

Tabela 2 - Caracterização da amostra

\begin{tabular}{ccc}
\hline Dados de Identificação & Subcategorias & $\%$ \\
\hline \multirow{2}{*}{ Gênero } & Feminino & 74,7 \\
& Masculino & 25,3 \\
\hline \multirow{2}{*}{ Categoria funcional } & Docente & 19,3 \\
& TAE & 80,7 \\
\hline \multirow{2}{*}{ Chefia } & Sim & 35,5 \\
& Não & 64,5 \\
\hline \multirow{2}{*}{ Situação funcional } & Ativo & 91,0 \\
& Aposentado & 9,0 \\
\hline \multirow{2}{*}{ Estado civil } & Solteiro(a) & 23,5 \\
& Casado(a) ou união estável & 65,1 \\
& Separado(a)/Divorciado(a) & 10,8 \\
& Viúvo(a) & 0,6 \\
\hline \multirow{2}{*}{ Tempo de trabalho } & Menos de 5 anos & 22,9 \\
& De 5 a 10 anos & 31,3 \\
& De 11 a 20 anos & 7,8 \\
& De 21 a 30 anos & 18,7 \\
& De 31 a 40 anos & 17,5 \\
& Mais de 41 anos & 1,8 \\
\hline
\end{tabular}




\begin{tabular}{ccc}
\hline & De $\mathrm{R} \$ 1.874,01$ a $\mathrm{R} \$ 3.748,00$ & 7,9 \\
\multirow{3}{*}{ Renda familiar mensal bruta } & $\mathrm{De} \mathrm{R} \$ 3.748,01$ a $\mathrm{R} \$ 9.370,00$ & 47,6 \\
& $\mathrm{De} \mathrm{R} \$ 9.370,01$ a $\mathrm{R} \$ 18.740,00$ & 36,1 \\
& $\mathrm{R} \$ 18.740,01$ ou mais & 8,4 \\
\hline Fonte: Elaborada pelas autoras, conforme os dados da pesquisa.
\end{tabular}

Em relação ao gênero dos participantes, os dados evidenciam um grande desequilíbrio, sendo que $74,7 \%$ dos respondentes são do gênero feminino e 25,3\% do gênero masculino. No que diz respeito à categoria funcional, também há grande desequilíbrio nos dados, uma vez que $80,7 \%$ dos respondentes são Técnicos Administrativos em Educação (TAEs) e apenas 19,3\% são docentes, o que pode ser justificado pelo fato de que a amostra foi selecionada a partir dos contatos das pesquisadoras, que são do gênero feminino e duas delas pertencem à categoria TAE.

No que diz respeito ao tempo de trabalho, os dados evidenciam que a maioria dos respondentes enquadra-se abaixo dos 10 anos, correspondendo a 54,2\% da amostra, sendo que $31,3 \%$ possui de 5 a 10 anos, e 22,9\%, menos de 5 anos de trabalho.

Já quanto à renda familiar mensal bruta, as duas faixas de maior representatividade foram a de $R \$ 3.748,01$ a $R \$ 9.370,00$, que consiste em $47,6 \%$ da amostra, seguida da faixa salarial de $R \$ 9.370,01$ a $R \$ 18.740,00$, representando $36,1 \%$ dos sujeitos.

Após a análise descritiva dos sujeitos da pesquisa, apresenta-se essa mesma forma de análise relativa aos construtos a seguir.

\subsection{Medida de Atitude em relação à Retaliação Organizacional - MARO}

Conforme mencionado, este estudo teve por base a escala MARO, de Mendonça e Tamayo (2003), que mede os componentes afetivo e conativo da atitude retaliatória. Assim, a apresentação desses resultados seguiu a ordem dos construtos comportamento afetivo (7 variáveis) e comportamento conativo (5 variáveis).

A dimensão afetiva faz referência à indignação diante do contexto organizacional, abrangendo, assim, a crença de que a injustiça provoca ressentimento, o que envolve o sentimento de seriedade da injustiça. Em relação à dimensão conativa, circunscreve a tendência consciente para reagir com a retaliação, reunindo a avaliação positiva das retribuições retaliatórias e englobando, então, a crença de que a organização merece a reação e que atuaria de forma semelhante perante 0 sentimento de injustiça (Mendonça, 2008).

As próximas tabelas indicam as médias das variáveis relacionadas a cada construto, ambas em ordem decrescente, apresentando o grau de concordância ou discordância dos respondentes em relação às frases afirmativas do modelo 
teórico. Destaca-se que a escala utilizada na pesquisa foi do tipo Likert, que varia de 1 (discordo totalmente) a 5 (concordo totalmente).

A Tabela 3 demonstra os dados da pesquisa relativos ao componente afetivo. Os dados demonstram que, à exceção da variável 11 - "Eu considero desprezível o que a instituição fez com João" (média 2,80) -, todas as demais variáveis apresentaram média superior a 3,0, confirmando, dessa forma, que os respondentes ficam indignados perante situações de injustiça na organização pesquisada (Mendonça, 2008). Quanto aos desvios apresentados pelo componente afetivo, eles variaram de 1,347 a 1,148. O menor desvio foi da variável VA5, com valor de 1,148 , e o maior desvio, para a variável VA10, com valor de 1,347.

Tabela 3 - Médias e desvios-padrão das variáveis do componente afetivo

\begin{tabular}{cccc}
\hline Variável & Componente afetivo & Média & Desvio \\
\hline VA3 & $\begin{array}{c}\text { Eu ficaria desapontado(a) se a instituição onde trabalho } \\
\text { agisse comigo da forma descrita. }\end{array}$ & 3,58 & 1,285 \\
\hline VA5 & $\begin{array}{c}\text { Eu acho que este tipo de situação faz com que as } \\
\text { pessoas que não foram beneficiadas sintam raiva. }\end{array}$ & 3,52 & 1,148 \\
\hline VA6 & $\begin{array}{c}\text { Eu ficaria insatisfeito(a) se a instituição onde trabalho } \\
\text { fizesse comigo a mesma coisa que fez com João. }\end{array}$ & 3,50 & 1,297 \\
\hline VA10 & $\begin{array}{c}\text { Eu ficaria decepcionado(a) se a instituição onde trabalho } \\
\text { fizesse comigo a mesma coisa. }\end{array}$ & 3,47 & 1,347 \\
\hline VA1 & Eu acho injusto o que a instituição fez. & 3,28 & 1,330 \\
\hline VA8 & Eu acho muito sério o que a instituição fez. & 3,27 & 1,345 \\
\hline VA11 & Eu considero desprezível o que a instituição fez com & 2,80 & 1,328 \\
& João. & & \\
\hline
\end{tabular}

Fonte: Elaborada pelas autoras, conforme os dados da pesquisa.

A Tabela 4, por sua vez, apresenta os dados relativos ao componente conativo.

Tabela 4 - Média e desvio-padrão das variáveis do componente conativo

\begin{tabular}{cccc}
\hline Variável & Componente conativo & Média & Desvio \\
\hline VC9 & Eu considero a reação de João justa. & 1,88 & 1,083 \\
\hline VC2 & Eu acho que a instituição mereceu o que João fez. & 1,81 & 1,088 \\
\hline VC12 & Eu acho que João está correto na maneira de agir. & 1,73 & 1,080 \\
\hline VC7 & Eu faria a mesma coisa que João fez. & 1,70 & 1,036 \\
\hline VC4 & Eu aprovo o que João fez. & 1,60 & 0,978 \\
\hline
\end{tabular}

Fonte: Elaborada pelas autoras, conforme os dados da pesquisa.

Em relação ao comportamento conativo, percebe-se que as médias obtidas em todas as variáveis ficaram entre 1,88 e 1,60. Dessa forma, segundo Mendonça (2008), os resultados indicam que os respondentes não possuem uma tendência consciente para reagir com a retaliação diante de uma situação de injustiça. Os desvios apresen- 
tados pelas variáveis do componente conativo variaram de 0,978 a 1,083, sendo o menor desvio para a variável VC4, que mede a aprovação da atitude de João.

A partir dos resultados obtidos por variáveis e seguindo a proposta dos autores da MARO, procedeu-se ao cálculo das médias gerais para cada dimensão (componente) da escala, ou seja, a média geral do componente afetivo e do componente conativo e o desvio-padrão. O desvio menor foi do componente conativo, com valor de 0,9328 , e o componente afetivo teve desvio no valor de 1,0455 . A Tabela 5 apresenta os resultados obtidos para as duas dimensões.

Tabela 5 - Comparação das médias entre componente afetivo e conativo

\begin{tabular}{ccc}
\hline Componente & Média & Desvio \\
\hline Componente afetivo & 3,3460 & 1,04556 \\
\hline Componente conativo & 1,7446 & 0,93280 \\
\hline
\end{tabular}

Fonte: Elaborada pelas autoras, conforme os dados da pesquisa.

De acordo com a interpretação dos resultados propostos pelos autores da MARO (Mendonça e Tamayo, 2003), se a média do comportamento afetivo for igual ou superior a 3,0 significa que os respondentes ficam indignados diante do contexto organizacional injusto. Assim, o resultado obtido no presente estudo aponta para média do componente afetivo de 3,3460, o que indica, portanto, que os respondentes ficaram indignados diante do contexto organizacional injusto apresentado através do cenário hipotético-conceitual.

Ainda segundo os autores, quanto ao componente conativo, se a média for inferior a 3,0, os respondentes não possuem tendência consciente para reagir de maneira retaliatória a situações de injustiça. Assim, nessa análise, com a média de 1,7446, concluise que os servidores respondentes não têm tendência a reagir de maneira retaliatória.

\subsection{Influências do perfil do respondente em relação à atitude retaliatória}

Um dos objetivos do trabalho é identificar como o perfil dos respondentes interfere na Medida de Atitude em relação à Retaliação Organizacional. Dessa forma, foram realizadas análises que buscaram estabelecer relações entre as variáveis de perfil dos participantes da pesquisa e os dois construtos da escala MARO.

Os procedimentos estatísticos consistiram em calcular as médias finais por segmento e, em seguida, realizar os testes estatísticos para verificar se as diferenças eram significativamente representativas. Foi realizado o Teste t para diferença de média entre sexo, sendo que os resultados não apontaram diferença para as 
médias. Entretanto, quando realizado o Teste t para ocupantes de cargos de chefia ou não, conforme dados apresentados na Tabela 6 , a grande maioria das variáveis, além das médias gerais dos componentes (afetivo e conativo), apresentou diferenças estatísticas significativas.

Tabelas 6 - Teste t para ocupantes de cargos de chefia

\begin{tabular}{|c|c|c|c|c|c|c|c|}
\hline \multirow[t]{2}{*}{ VA } & \multirow[t]{2}{*}{ Afirmação } & \multirow[t]{2}{*}{$\begin{array}{l}\text { Ocupa } \\
\text { cargo } \\
\text { chefia }\end{array}$} & \multirow[t]{2}{*}{ Média } & \multirow[t]{2}{*}{ Desvio } & \multicolumn{2}{|c|}{$\begin{array}{c}\text { Levene's } \\
\text { Test for } \\
\text { Equality of } \\
\text { Variances } \\
\end{array}$} & \multirow{2}{*}{\begin{tabular}{|c}
$\begin{array}{c}\text { T-test for } \\
\text { Equality of } \\
\text { Means }\end{array}$ \\
$\begin{array}{c}\text { Sig. } \\
\text { (2-tailed) }\end{array}$ \\
\end{tabular}} \\
\hline & & & & & $\mathrm{F}$ & Sig. & \\
\hline \multirow[t]{2}{*}{1} & $\begin{array}{l}\text { Eu acho injusto o que a } \\
\text { instituicão fez com João. }\end{array}$ & Sim & 3,00 & 1,23 & 939 & ,334 & ,041 \\
\hline & & Não & 3,44 & 1,36 & & & ,036 \\
\hline \multirow[t]{2}{*}{2} & $\begin{array}{l}\text { Eu acho que a instituição } \\
\text { mereceu o que João fez. }\end{array}$ & Sim & 1,58 & 0,89 & 2,692 & 103 & ,037 \\
\hline & & Não & 1,94 & 1,16 & & & ,025 \\
\hline \multirow[t]{2}{*}{3} & $\begin{array}{c}\text { Eu ficaria desapontado(a) se } \\
\text { a instituição onde trabalho } \\
\text { agisse comigo da forma } \\
\text { descrita. }\end{array}$ & Sim & 3,29 & 1,20 & 289 & ,592 & ,027 \\
\hline & & Não & 3,75 & 1,30 & & & ,024 \\
\hline 4 & Eu aprovo o que João fez. & $\begin{array}{l}\text { Sim } \\
\text { Não }\end{array}$ & $\begin{array}{l}1,37 \\
1,72\end{array}$ & $\begin{array}{l}0,66 \\
1,09\end{array}$ & 17,158 & ,000 & $\begin{array}{l}, 028 \\
.012\end{array}$ \\
\hline \multirow[t]{2}{*}{5} & $\begin{array}{l}\text { Eu acho que este tipo de } \\
\text { situação faz com que as } \\
\text { pessoas que não foram } \\
\text { beneficiadas sintam raiva. }\end{array}$ & Sim & 3,22 & 1,24 & 4,365 & ,038 & 011 \\
\hline & & Não & 3,69 & 1,05 & & & ,016 \\
\hline \multirow[t]{2}{*}{6} & $\begin{array}{l}\text { Eu ficaria insatisfeito(a) se } \\
\text { a instituição onde trabalho } \\
\text { fizesse comigo a mesma } \\
\text { coisa que fizeram com João. }\end{array}$ & Sim & 3,14 & 1,26 & 361 & ,549 & ,007 \\
\hline & & Não & 3,70 & 1,27 & & & ,007 \\
\hline \multirow[t]{2}{*}{7} & $\begin{array}{l}\text { Eu faria a mesma coisa que } \\
\text { João fez. }\end{array}$ & Sim & 1,49 & 0,85 & 7,723 & ,006 & 055 \\
\hline & & Não & 1,81 & 1,10 & & & ,040 \\
\hline \multirow[t]{2}{*}{11} & $\begin{array}{c}\text { o que a instituição fez com } \\
\text { João }\end{array}$ & Sim & 2,46 & 1,30 & 347 & ,556 & 015 \\
\hline & & Não & 2,98 & 1,31 & & & ,015 \\
\hline \multirow[t]{2}{*}{ A } & $\begin{array}{c}\text { MEDIA DO COMPONENTE } \\
\text { AFETIVO }\end{array}$ & Sim & 3,08 & 0,95 & ,771 & ,381 &, 015 \\
\hline & & Não & 3,49 & 1,07 & & & ,012 \\
\hline C & $\begin{array}{l}\text { MIEDIA DONATIVO } \\
\text { CONIE }\end{array}$ & Sim & 1,53 & 0,73 & 9,428 & ,003 & ,035 \\
\hline
\end{tabular}

Fonte: Elaborada pelas autoras, a partir dos dados da pesquisa.

A variável "Eu acho injusto o que a empresa fez com João" (VA1) apresenta média significativamente maior entre os respondentes que não ocupam cargo de 
chefia $(3,44)$ comparativamente à média dos que ocupam $(3,00)$. O mesmo foi verificado com a variável "Eu acho que a instituição mereceu o que João fez" (VC2), na qual os que não ocupam cargo avaliaram com média de 1,94, e os ocupantes de cargo de chefia, com média de 1,58. As variáveis VA8, VC9 e VA10 não apresentaram diferenças significativas nas médias. Todas as demais variáveis apresentam o mesmo comportamento, com diferenças significativas entre ocupantes de cargos de chefia e não ocupantes.

Dessa forma, em síntese, as respostas dos servidores que não ocupam cargos de chefia indicam maior indignação à situação apresentada, tanto na dimensão afetiva como na conativa.

Analisando os dados das médias apresentados na Tabela 6, pode-se afirmar que o fato de o respondente ocupar cargo de chefia implica avaliação mais positiva do que a avaliação dos respondentes que não ocupam cargo de chefia.

\section{CONSIDERAÇÕES FINAIS}

O problema de pesquisa proposto neste estudo foi verificar como os servidores de determinada instituição federal de ensino superior reagiriam diante de uma situação de injustiça no trabalho. Com base nos achados da pesquisa e seguindo a orientação de Mendonça e Tamayo (2003), pode-se concluir que, com relação à atitude retaliatória vinculada à dimensão afetiva, os resultados apontam para uma indignação por parte dos servidores respondentes diante do contexto hipotéticoconceitual apresentado. Soma-se à conclusão de que a dimensão conativa indica que os servidores não possuem tendência consciente para reagir de maneira retaliatória a situações de injustiça.

Quanto à resposta para um dos objetivos específicos - se o perfil dos respondentes interfere nas atitudes retaliatórias -, os resultados demonstraram que não existe diferença de atitudes entre homens e mulheres. Contudo o mesmo não se pode dizer da diferença entre ocupantes de cargos de chefia e não ocupantes, pois, nesta análise, foi demonstrado que os primeiros tendem a ter uma atitude mais positiva do que os segundos, ou seja, demonstram tendência a um comportamento menos retaliatório.

Os resultados sugerem que a temática deve ser aprofundada no âmbito da própria instituição, bem como em outras instituições públicas, ampliando os estudos relacionados às estratégias específicas de organizações, ou seja, identificando medidas que possam contribuir para minimizar os efeitos da retaliação organizacional. As análises que buscaram identificar relações entre as variáveis de 
perfil dos participantes da pesquisa e a medida da atitude de retaliação fornecem informações relevantes para a área de gestão de pessoas. Os resultados podem sugerir que a atuação junto aos servidores que ocupam ou não cargos de chefia também pode ser diferenciada.

Como limitação deste trabalho, pode-se apontar a utilização de uma amostra não probabilística por conveniência, motivo pelo qual as discussões apresentadas não permitem generalizações. Nesse sentido, sugere-se que o estudo seja ampliado, a fim de abranger um maior número de servidores e obter uma amostra mais representativa. Surge ainda a necessidade de novas pesquisas sobre o tema, que poderiam relacionar a MARO com outros construtos dos estudos organizacionais, como a Justiça Organizacional, analisando a relação entre as dimensões de justiça com a atitude de retaliação. Outra sugestão é explorar a ampliação da escala para a dimensão cognitiva de atitude, uma vez que a escala original não abarca esse aspecto.

\section{REFERÊNCIAS}

Adams, J. S. (1963). Toward and understanding of inequity. Journal of Abnormal Social Psychology, 67(5), 422-426.

Assmar, E. M. L., Ferreira, M. C., \& Souto, S. O. (2005). Justiça organizacional: uma revisão crítica da literatura. Revista Psicologia: reflexão e crítica, 18(3), 443-453.

Gil, A. C. (2008). Métodos e técnicas de pesquisa social. São Paulo: Atlas.

Lakatos, E. M., \& Marconi, M. A. (2011). Metodologia científica (6. ed.). São Paulo: Atlas.

Matias-Pereira, J. (2016). Manual de metodologia da pesquisa científica. (4. ed.). São Paulo: Atlas.

Mendonça, H. (2008). Atitudes retaliatórias. In M. M. M. Siqueira (Org.). Medidas do comportamento organizacional: ferramentas de diagnóstico e de gestão (pp. 249-263). Porto Alegre: Artmed.

Mendonça, H. et al. (2004). Percepção e julgamento da retaliação organizacional: construção e validade fatorial de um instrumento. Estudos de Psicologia, 9(3), 543-551.

Mendonça, H., \& Tamayo, A. (2003). Construção e validação de uma medida de atitude em relação à retaliação organizacional (MARO). Avaliação psicológica, 2(2), 147-153.

Mendonça, H., \& Tamayo, A. (2004). Percepção de Justiça e Reações Retaliató- 
rias nas Organizações: análise empírica de um modelo atitudinal. Revista de Administração Contemporânea, 8(2), 117-135.

Mendonça, H., \& Tamayo, A. (2008). Valores pessoais e retaliação organizacional: estudo em uma organização pública. Revista de Administração Contemporânea, 2(2), 189-200.

Rego, A. (2001). Percepções de justiça: estudos de dimensionalização com professores do ensino superior. Psicologia: Teoria e Pesquisa, 17(2), 119-131.

Skarlicki, D. P., \& Folger, R. (1997). Retaliation in the workplace: the roles of distributive, procedural, and interactional justice. Journal of Applied Psychology, 82(3), 434-443.

Towsend, J., Phillips, J. S., \& Elkins, T. J. (2000). Employee retaliation: the neglected consequences of poor leader-member Exchange relations. Journal of Occupational Health Psychology, 38(4), 457-463.

UFSM - Universidade Federal de Santa Maria. (2017). Pró-Reitoria de Planejamento - PROPLAN. Santa Maria: UFSM. Recuperado de https://portal.ufsm. $\mathrm{br} /$ indicadores/select/27. 